\title{
Medical students talk openly about their mental health challenges
}

A group of medical students at Western University in London, Ontario, is getting proactive about helping classmates with an extremely sensitive issue: mental health problems. Late last term, 60 students about a fifth of all the 260 first- and second-year students at the London campus of the Schulich School of Medicine and Dentistry - gathered in a lecture hall for a presentation reminiscent of an Alcoholics Anonymous meeting. In brutally frank detail, several students stood up and talked about their personal lives, revealing histories of depression, anxiety, bulimia and self-harm. They described how those issues affected their lives, and how they are managing now.

Most important, they told their classmates that mental health problems are nothing to be ashamed of - they can happen to anybody, including medical students.

There is no data about the prevalence of mental health issues among Canadian medical students. However, studies from the United States, Australia and Britain place the rate of depression among medical students as high as $20 \%$; between $6 \%$ and $10 \%$ report suicidal ideation. Later this year, the Canadian Federation of Medical Students (CFMS) plans to survey students at all 17 medical schools in Canada with the hope of garnering the first national data on this subject.

For students who are suffering alone, peer-to-peer forums, such as Schulich's, offer a point of entry for seeking help before serious intervention is needed. Students Jeremy Chitpin and Amanda Sauvé, who organized the Schulich event, agree the stigma of seeing a psychiatrist, taking antidepressants or even admitting to having a mental health issue — "the fear of our peers" - is by far the biggest hurdle to overcome.

Chitpin estimates that half of students who attended the forum have had mental health struggles. In interviews, Chitpin, Sauvé and other students said they have to feel safe talking about what's going on inside their minds. They said they become more comfortable discussing their problems when they hear

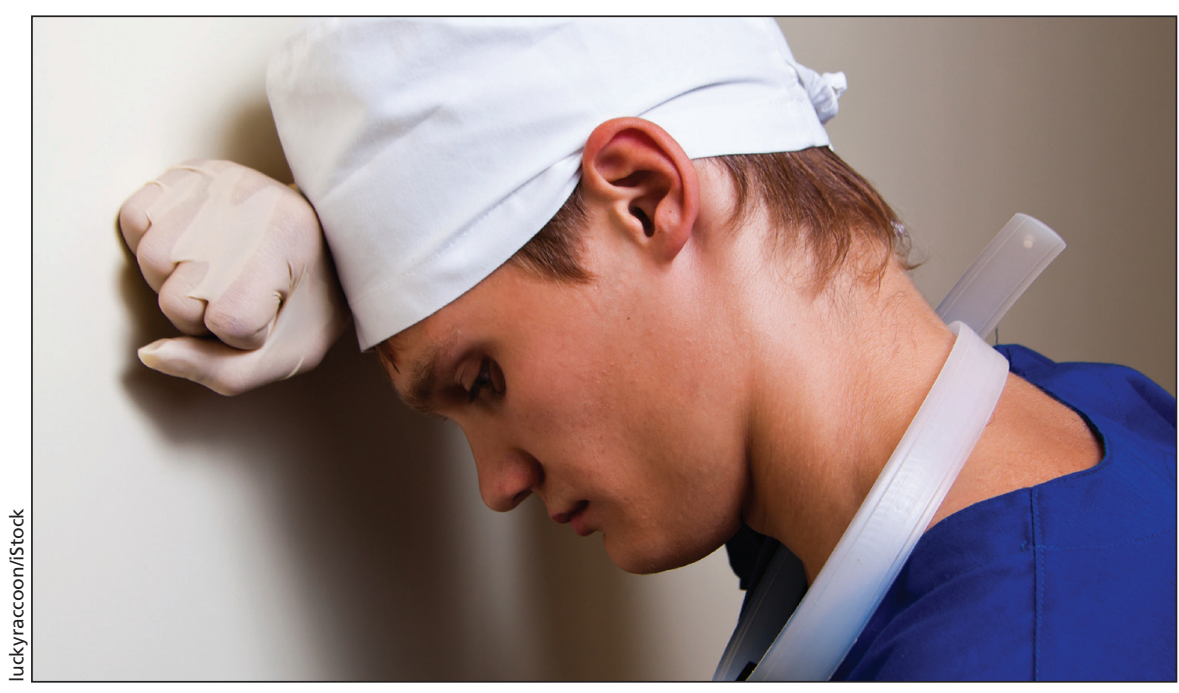

Studies in some countries indicate that up to $20 \%$ of medical students have depression.

classmates share their mental health experiences. Having one or two trusted friends or classmates can often provide vital support.

Following Schulich's forum, a student who asked not to be named told CMAJ she has struggled with depression "as long as I can remember." She spoke of her suicidal ideations and a history of self-harm. "The stigma is something that needs to be fought against, and when I heard that Jeremy was doing this open session, it sounded like a nice opportunity. I wanted to be a part of it and offer my input," she said.

Although all medical schools in Canada have some form of "health and wellness" services, Brandon Maser, spokesperson for the CFMS and fourthyear student at Queen's University, in Kingston, Ontario, said there is much variability in the success of these services. Schulich is the first school to offer a large-scale, open forum. Students at Schulich are planning to hold similar forums in this academic year. Another program, similar to one at Queen's, will offer mental health discussion and support groups for students in their clerkship years.

Psychiatrist, Dr. Derek Puddester, an associate medical director with the Ontario Medical Association's physician health program, praised the Schulich initiative, but had strong recommen- dations for students who encounter classmates with mental health issues: "Be a good colleague but don't become a care provider," he advised. "Let troubled students know they are being supported, and encourage them to get professional care if needed."

Mental health problems carry less of a stigma for younger people, he adds, and while millennials are much more open to seeking help, there is still work to do. One thing these students needn't worry about is whether a history of mental health struggles will affect their professional licensure. Dr. Michael Myers, an expert in physician health at the State University of New York, in Brooklyn, said a licensing body is concerned with whether any health issue, mental or otherwise, has been identified and is being managed appropriately.

Whether these mental health challenges are addressed with the involvement of faculty and student health services, or through student-led, peer-to-peer support groups, it is crucial that medical students recognize, and get treatment for these issues as early as possible in their careers. As with all other areas in health care, early intervention offers the best opportunity to catch a problem before it reaches the acute, or crisis stage. Cameron Johnston, London, Ont. 